\title{
Effect of Asphalt Mortar Composition on Dynamic Response of Asphalt Mixture
}

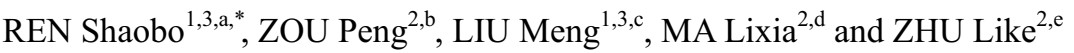 \\ ${ }^{1}$ Guangxi Key Lab of Road Structure and Materials, No.6 High-tech 2nd Road,Nanning,China \\ ${ }^{2}$ Key Laboratory for Special Area Highway Engineering of Ministry Of Education, Chang'an \\ University, Middle Section of Nan Erhuan Road, Xi'an, China \\ ${ }^{3}$ Guangxi Transportation Research Institute, No.6 High-tech 2nd Road, Nanning,China \\ a409258643@qq.com , '591064139@qq.com, '547086937@qq.com, \\ d1010824593@qq.com, e384396514@qq.com
}

\begin{abstract}
To investigate the effect of mortar composition on visco-elastic response of asphalt mixture, The Asphalt Mixture Performance Test (SPT) was conducted on several asphalt mixtures for different ratios of filler to asphalt (F/A), fiber dosage and proportion of cement instead of mineral powder. The effect of F/A, fiber dosage and and proportion of cement replacement on visco-elastic mechanical parameters (dynamic modulus and phase angle) of asphalt mixtures are analyzed. The results indicate that the dynamic modulus of asphalt mixtures increases first and then decreases with the increases in F/A and fiber dosage. And the more significant differences in these dynamic moduli appear at the higher the load frequency. The asphalt mixture with the lowest F/A has the biggest phase angle, and the difference in the phase angles of those asphalt mixtures is not significant. The changes of phase angle have a close relationship with the load frequency. The resistance to permanent deformation of asphalt mixture can be greatly enhanced by adding fiber. The effect of cement instead of mineral powder on the viscoelastic property of asphalt mixture is relatively small, while the resistance to high-temperature deformation of asphalt mixture can be improved to some extent.
\end{abstract}

\section{Introduction}

Asphalt mixture is a multiphase composite material consisting of mineral aggregate and asphalt, the mortar consist of mineral powder, fiber, cement, lime and other filler largely affect the visco-elastic properties of asphalt mixture. In recent years, many researchers have carried out studies of asphalt cement and visco-elastic properties of asphalt mixture.Little[1] uses model for visco-elastic to simulate the creep behavior of asphalt mixture; Schwartz[2] gets the visco-elastic parameters of asphalt mixture by creep test; Li $[3,4]$ analyzed the effect of temperature and loading frequency to visco-elastic response of asphalt mixture; Zhou[5] analyzed the relationship between visco-elastic parameters and performance of

* Corresponding author: 409258643@qq.com 
asphalt mixture. Hou [6] studied visco-elastic properties of asphalt mastic by static creep experiment. Garcia[7] studied the healing properties of asphalt mortar; Li [8], Yin[9] researched viscosity characteristics and rheological characteristics of the asphalt mortar from different perspectives. However, the impact of composition and characteristics of mortar to visco-elastic response of asphalt mixture is not clear. In this paper, by asphalt mixture performance test (AMPT), adding different proportions of fiber, cement and F/A, test study have been done on mechanical properties of the asphalt mixture, and analyzed the influence of fibers, cement content and flour glue than to asphalt mixture on visco-elastic parameters ,such as dynamic modulus, phase angle, frequency and flow time flow

\section{Experimental Materials}

Asphalt mixture was prepared by Using Zhonghai 90 \# asphalt, technical characteristics of asphalt are shown in Table 1. Basalt was chosen to be the aggregate, the relative density of the aggregate are shown in Table 2 and 3, the mineral powder of limestone was used as a filler. three kinds of combinations ways, mineral powder, mineral powder + fiber and mineral powder +cement, were used to prepare mortar of Asphalt . asphalt mixture of different compositions of mortar were mixed , using Grading of AC-20 (listed in Table 4), wherein ,F/A of the three groups were $1.583,1.454,1.345$; fiber content were $0.15 \%, 0.3 \%$ $0.45 \%$; cement was used to replace a part of the mineral powder, the ratio of the mineral powder and cement was $1: 2,1: 2.5,1: 3$.

Table 1 Basic Properties Of Asphalt

\begin{tabular}{|c|c|c|c|c|}
\hline Test Items & Values & \multicolumn{2}{|c|}{ Test Items } & Values \\
\hline Penetration $[1 / 10 \mathrm{~mm}]$ & 86 & filmy heating & Mass loss[\%] & 0.04 \\
\cline { 1 - 1 } Softening point $\left[{ }^{\circ} \mathrm{C}\right]$ & 45.5 & operational test & Penetration ratio[\%] & 76.3 \\
\cline { 1 - 1 } \cline { 5 - 5 } ductility $[\mathrm{cm}]$ & $>150$ & $\left(163^{\circ} \mathrm{C}, 5 \mathrm{~h}\right)$ & ductility $[\mathrm{cm}]$ & $>150$ \\
\hline
\end{tabular}

Table 2 Relative Density Of Coarse Aggregate

\begin{tabular}{|c|c|c|c|c|c|}
\hline the sizes of screen holes $(\mathrm{mm})$ & 19.0 & 16.0 & 13.2 & 9.5 & 4.75 \\
\hline the bulk volume relative density $(\mathrm{Gsb})$ & 2.735 & 2.733 & 2.739 & 2.717 & 2.714 \\
\hline
\end{tabular}

Table 3 Relative Density Of Fine Aggregate

\begin{tabular}{|c|c|c|c|c|c|c|}
\hline the sizes of screen holes (mm) & 2.36 & 1.18 & 0.6 & 0.3 & 0.15 & 0.075 \\
\hline apparent relative density (Gsa) & 2.796 & 2.773 & 2.773 & 2.765 & 2.717 & 2.731 \\
\hline
\end{tabular}

Table 4 Mineral Aggregate Gradation

\begin{tabular}{|c|c|c|c|c|c|c|c|c|c|c|c|c|}
\hline \multirow{3}{*}{ gradation } & \multicolumn{10}{|c|}{ Passing rate (\%) } \\
\cline { 2 - 12 } & $\begin{array}{c}26.5 \\
\mathrm{~mm}\end{array}$ & $\begin{array}{c}19 \\
\mathrm{~mm}\end{array}$ & $\begin{array}{c}16 \\
\mathrm{~mm}\end{array}$ & $\begin{array}{c}13.2 \\
\mathrm{~mm}\end{array}$ & $\begin{array}{c}9.5 \\
\mathrm{~mm}\end{array}$ & $\begin{array}{c}4.7 \\
5 \\
\mathrm{~mm}\end{array}$ & $\begin{array}{c}2.3 \\
6 \\
\mathrm{~mm}\end{array}$ & $\begin{array}{c}1.1 \\
8 \\
\mathrm{~mm}\end{array}$ & $\begin{array}{c}0.6 \\
\mathrm{~mm}\end{array}$ & $\begin{array}{c}0.3 \\
\mathrm{~mm}\end{array}$ & $\begin{array}{c}0.15 \\
\mathrm{~mm}\end{array}$ & $\begin{array}{c}0.075 \\
\mathrm{~mm}\end{array}$ \\
\hline AC-20 & 100 & 99.2 & 90.2 & 76 & 62.2 & 37 & $\begin{array}{c}26 . \\
7\end{array}$ & $\begin{array}{c}18 . \\
3\end{array}$ & $\begin{array}{c}12 . \\
6\end{array}$ & 8.1 & 5.9 & 5 \\
\hline
\end{tabular}




\section{Test Method}

Performance tests of asphalt mixture have been researched extensively, many testing methods have been proposed, such NCHRP-9-19 research programs, which developed the test methods for asphalt mixture SPT, proposing that mechanics parameters ,such as dynamic modulus and phase angle [10].According to the specification of AASHTO TP79, sine-wave was loaded. The level of stress, corresponds micro strain from 50 to 150 ; testing temperature is $25{ }^{\circ} \mathrm{C}$; loading frequencies are $0.01,0.1,0.2,0.5,1,2,5,10,20,25 \mathrm{~Hz}$, the effect of mortar composition on visco-elastic response of asphalt mixture was analyzed according dynamic modulus $\left(\mathrm{E}^{*}\right)$ and phase angle $(\delta)$.

\section{Analysis and Discussion}

\subsection{Effect of F/A in Mortar on Visco-elastic of Asphalt Mixture}

The mineral powder has a larger specific surface area, surface area of mineral powder typically accounts for more than $80 \%$ of the total area of mineral mixture in asphalt mixture. In the same amount of asphalt, due to the presence of mineral powder, formed asphalt film is thin, the proportion of framework asphalt is larger, prompting the aggregate particles of mineral can be bonded firmly to form a higher overall strength. With the increase in filler-asohalt ratio (F/A), the effect of mineral powder gradually increases in asphalt, such as volume enhanced, reactions in physical and chemical, thus the consistency of mortar increases, high temperature stability of mortar significantly is enhanced. Here, to in-depth analysis the effect of F/A on the visco-elastic of asphalt mixture, using SPT test measures dynamic modulus and phase angle in different $F / A$ and asphalt-aggregate ratio $(A s / A g)$ of asphalt mixture as shown in Fig. 1.

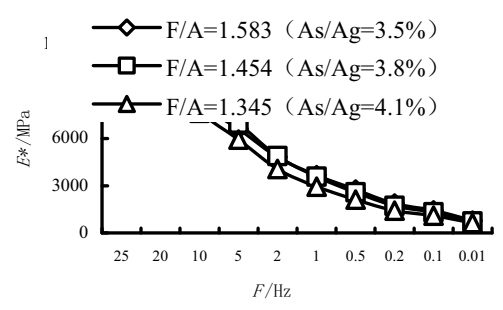

(a) $E^{*}$

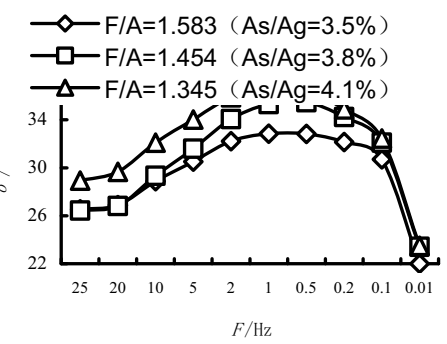

(b) $\delta$

Fig. 1 dynamic modulus( $\left(E^{*}\right)$ and phase angle $(\delta)$ with different F/A of asphalt mixture

As it can be seen from Fig.1, with the increase of F/A, dynamic modulus of asphalt mixture changes consistently at different frequencies, the asphalt mixture, in the middle of F/A that is 1.454 , has the highest dynamic modulus, in other words, the dynamic modulus with the increase of F/A increase first and then decrease, and the higher the frequency ,the greater the dynamic modulus of discrimination; the asphalt mixture has the maximum of phase angle when F/A is small, with increase of loading frequency, the phase angle of asphalt mixture, of which F/A are 1.454 and 1.583 ,gradually converge, the difference of phase angle is smaller at higher F/A. 


\subsection{Effect of Fiber Content in Mortar on Visco-elastic of Asphalt Mixture}

Unique structure of fiber, hollow and elongated, not only can absorb and stabilize the asphalt, but also played the role of reinforcement, making asphalt mortar shows good high temperature stability. SPT test results of asphalt mixture added different amount of fiber shown in Fig.2.

Fig.2(a) shows that dynamic modulus of asphalt mixture would decreases with the loading frequency reducing. For the same loading frequency of asphalt mixture, when the fiber content increasing, dynamic modulus increased at the first and then decreased, and the loading frequency higher, the difference of dynamic modulus more significant. Dynamic modulus of asphalt mixture would be maximum when adding $0.15 \%$ fiber to it, and the elastic is the best ; and the dynamic modulus of asphalt mixture are less than without fiber when fiber content are $0.3 \%$ and $0.45 \%$. Fig. 2 (b) shows the change of phase angle is more complex, closely relating to the loading frequency. When loading frequency within $25 \mathrm{~Hz}-10 \mathrm{~Hz}$, phase angle did not change significantly after adding fiber; When loading frequency in range of $10 \mathrm{~Hz}-0.1 \mathrm{~Hz}$, phase angle significantly attenuated after adding fiber, the visco-elastic of mixture increased, but difference of phase angle is small with different fiber content in mixture; when loading frequency is $0.01 \mathrm{~Hz}$, the phase angle is increased after the addition of fiber increasing.

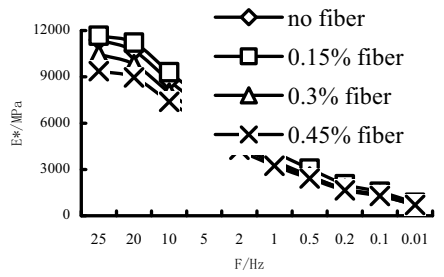

(a) $E^{*}$

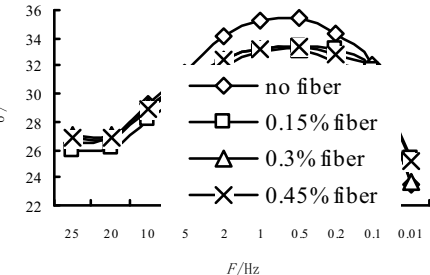

(b) $\delta$

Fig.2 dynamic modulus and phase angle of asphalt mixture for different fiber contents

\subsection{Effect of cement replacing amounts of mineral powder in mortar on visco-elastic of asphalt mixture}

By SPT test, the influence of adding amounts of cement in cement mortar on visco-elastic of asphalt mixture is analyzed. The dynamic modulus and phase angle of asphalt mixture, which were added into different amount of cement, were shown in Fig.3.

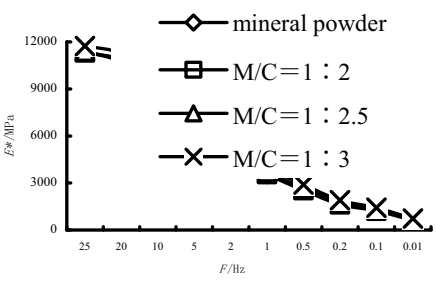

(a) $E^{*}$

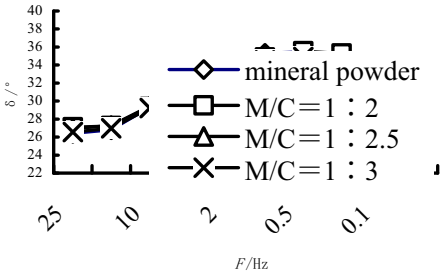

(b) $\delta$

Fig.3 dynamic modulus and phase angle of asphalt mixture in different adding amounts of cement 
Fig.3 (a) shows that the dynamic modulus of asphalt mixture would increase with the increase in mineral powder-cement ratio $(M / C)$ after adding the cement to asphalt mortar, especially when $M / C=1: 3$ is more obvious, indicating that the elasticity of asphalt mixture can be improved by adding the cement to asphalt mortar , thereby improving high-temperature performance of asphalt mixture to a certain extent. Fig.4 (b) shows that, phase angle variation of asphalt mixture is not clear under high loading frequency after adding the cement to asphalt mortar, indicating that it is little effect to increase the viscosity of the asphalt mixture by adding the cement to asphalt mortar; when the loading frequency are $0.01 \mathrm{~Hz}$ and $0.1 \mathrm{~Hz}$, after adding the cement, the phase angle increases, the viscosity decreases.

\section{Conclusions}

(1) With the increase in F/A, dynamic modulus of asphalt mixture changes consistently at different frequencies, the dynamic modulus with the increase in F/A increase first and then decrease, and the higher the frequency, the greater the dynamic modulus of discrimination; the asphalt mixture has the maximum of phase angle when F/A is small, the difference of phase angle in asphalt mixture is smaller at higher F/A.

(2) For the same loading frequency of asphalt mixture, when the fiber content increasing, dynamic modulus increased at the first and then decreased, and the loading frequency higher, the difference of dynamic modulus more significant. The change of phase angle is more complex, closely relating to the loading frequency.

(3) The dynamic modulus of asphalt mixture would increase with the amount of cement increasing after replacing mineral powder with cement, the dynamic modulus of asphalt mixture has the maximum when $\mathrm{M} / \mathrm{C}=1: 3$, the change of dynamic modulus is not outstanding on other scale, the phase angle variation of asphalt mixture is not clear, the effect of replacing mineral powder with cement is quite small to the viscosity of the asphalt mixture.

\section{Acknowledgments}

This work is supported by the Open Fund of Guangxi Key Lab of Road Structure and Materials (2014gxjgclkf-001), Applied basic research project the ministry of transport of China (No. 2014319812151) and Natural Science Basic Research Plan in Shaanxi Province of China (No. 2014JQ7242). The authors gratefully acknowledge their financial support.

\section{References}

1. Little, D.N., Button, J.W. and Youssef, H., "Development of criteria to evaluate uniaxial creep data and asphalt concrete permanent deformation potential", Transportation Research Record, Vol. 1471, 1993, pp.49-57.

2. Schwartz, C.W., Gibson, N.H., Schapery, R. A. and Witczak, M. W., "Viscoplasticity Modeling of Asphalt Concrete Behavior", The 15th ASCE Engineering Mechanics Conference. ASCE, New York, 2002, pp.144-159.W. Strunk Jr., E.B. White, The Elements of Style, third ed., Macmillan, New York, 1979.

3. Li, P. L., Ding, Z., and Zhang, Z. Q., "Effect of Temperature and Frequency on Visco-Elastic Dynamic Response of Asphalt Mixture," Journal of Testing and Evaluation, Vol. 41, No. 4, 2013, pp. 571-578.

4. LI Pei-long, ZHANG Zheng-qi, WANG Bing-gang. Analysis of visco-elastic response influencing factors of asphalt mixture[J]. Journal of Zhengzhou University 
(Engineering Science), 2010, 31(3):96-100.

5. Zhou, Z.G. and Fu, B. F., "Applying the theory of visco- elasticity to evaluate thermal stability of asphalt mixtures", Journal of Highway and Transportation Research and Development, Vol. 22, No.11, 2005, pp.54-56.

6. Hou, H. J., Hu, X. G. Study on Static Creep Test for Viscoelastic Property of Asphalt Mastic. [J] Journal of Building Materials. 2008,11(3):292-298.

7. Garcia A.. Self-healing of open cracks in asphlt mastiic. The science and technology of fuel and energy, 2012,93:264-272.

8. Li P., Zhang Z.Q., Sun H. W and Wang B. G. Research on viscosity property of asphalt mortar [J]. Journal of Traffic and Transportation Engineering, 2008, 8 (2) : 49-52.

9. Yin Y. M., Zhang X. N. Research on high temperature rheological characteristics of asphalt mastics with indonesian Buton Rock Asphalt( BRA) [J]. Journal of Wuhan University Of Technology, 2010,32(7):85-89.

10. Kaloush K.E., "Simple Performance Test for Permanent Deformation of Asphalt Mixture", PhD Dissertation of Arizon State University, Ann Arbor, USA, 2001. 